\title{
Optimization of the in vitro release of zomepirac from suspensions and suppositories
}

\author{
J.G. Fokkens ${ }^{1.2}$, C.J. De Blaey ${ }^{2}$, R.R. Niederer ${ }^{3}$ and H.W. Zulliger ${ }^{3}$ \\ 'Duphar, 1381 CP Weesp; 'Deparment of Pharmaceutics, University of Utrecht, Utrech1 (The \\ Netherlands); and ${ }^{3}$ Cilag AG (Switzerland) \\ (Received October 13th, 1983) \\ (Accepted November 29th, 1983)
}

\section{Summary}

In an in vitro study the release rates of zomepirac acid (I) and zomepirac sodium dihydrate (II) from suspensions in liquid paraffin towards an aqueous phase were determined. When calcium was added to the aqueous phase a cake of zomepiraccalcium was formed at the interface paraffin/buffer and the release rates of I and/or II decreased extensively. The influence of additives, i.e. Tween 80, PVP and lecithin, in the suspension on this caking process was determined. It was found that Tween 80 was the most effective additive. The results obtained were 'transformed' to the release of II from suppositories (in vitro studies in a modified Paddle set-up). Again Tween 80 was the most effective additive; the influence of lecithin and PVP was negligible.

\section{Introduction}

The bioavailability of a drug after rectal administration in a suppository is sometimes incomplete and irregular. Causes of this irregular drug uptake are, among other things, variability in the spreading of the base, problems concerning the release of drug from the vehicle, dissolution of the drug and interactions between drug and vehicle compounds or physiological agents. Bioavailability studies with zomepirac showed a relatively low concentration in the blood after rectal application ${ }^{1}$. Further research pointed to an interaction of zomepirac with (physiologically) present Correspondence: J.G. Fokkens. Duphar WNH. 3, C.J. van Houtenlaan 36, 1381 CP Weesp, The Netherlands.

' Cilag AG, internal report. 
calcium. It was shown that zomepirac reacts with calcium to form an almost insoluble salt. The formation of such a salt may in principle cover the entire interface between suppository and rectal fluid, which then results in a decreased release of zomepirac. This supposition is based on a similar phenomenon observed with phenobarbital; when phenobarbital sodium is released from a paraffin suspencion towards an aqueous phase with low $\mathrm{pH}(<5)$, a cake of phenobarbital is formed at the paraffin/buffer interface (Fokkens and De Blaey, 1982).

The purpose of the present study was to improve the pharmaceutical availability of zomepirac administered in suppositories. To this end a study was made of the release rates of zomepirac from paraffin suspensions in a model apparatus and the results obtained were then extrapolated to various suppository bases. Two chemical forms of zomepirac, i.e. the acid and the sodium salt, were used.

\section{Materials and Methods}

\section{Materials}

A summary of the compounds used in this study is presented in Table 1.

The aqueous phase used consisted of either demineralized water or buffer. The $\mathrm{pH}$ of the buffers was always 7.4. The liquid paraffin used was European Pharmacopoeia grade and had a viscosity of $71 \pm 0.1 \mathrm{mPas}$.

\section{Methods}

\section{Experiments with suspensions}

Suspensions of zomepirac in liquid paraffin were prepared as descrihed before (Fokkens and De Blaey, 1982). Suspensions of zomepirac sodium dihydrate were prepared in the same way, but the relative humidity of the air was approximately $50 \%$ (less than $15 \%$ in previous experiments). After their preparation the suspensions were rotated 'end over end' $(80 \mathrm{rpm})$ for at least $45 \mathrm{~min}$. Then they were carefully

\section{IABLF 1}

\begin{tabular}{|c|c|c|}
\hline Compound & $M_{1} "$ & Quality batch number \\
\hline Calcium chluride dihydrate & 147.02 & pro analysi \\
\hline Di-sodium-hydrogen phosphate dihydrate & 177.99 & European Pharmacopicia grade \\
\hline Lecithin & $\ldots$ & soya lecithin \\
\hline Polyvinylpyrrolidonc & -24.500 & French Pharnacopocia grade \\
\hline Potassium dihydrogen phosphate & 136.09 & pro analysi \\
\hline Tris (hydroxymethyl) aminomethane & 121.14 & pro analysi \\
\hline Tween 80 & - & European Pharmacopocia grade \\
\hline Zomepirac acid ${ }^{b}$ & 291.72 & Pure quality; batch mo. 822019 \\
\hline Zomepirac sodium dihydrate" & 349.71 & Pure quality; batch no. 027268 \\
\hline
\end{tabular}

"Relative molecule mass.

"Kindly supplied by Cilag AG, Schafthausen. Switzerland. 
poured on top of the aqueous phase in the in vitro apparatus. This apparatus (see Fokkens and De Blaey. 1982) consisted of: (1) a $800 \mathrm{ml}$ beaker, containing $640 \mathrm{~g}$ of the aqueous phase; (2) a specially shaped stirrer, rotating at $60 \mathrm{rpm}$; and (3) an open glass tube with a diameter of $37.6 \mathrm{~mm}$, mounted in such a way that the distance between the bottom of this tube and the paraffin/bulk fluid interface was at least 2 $\mathrm{mm}$.

Approximately $10 \mathrm{~g}$ of the suspension was poured into the open glass tube and the sampling procedure was started. Samples were taken at pre-set time intervals, using an automatic sampling apparatus (ASA Ismatec, Zurich). The volume of the withdrawn sample was automatically replaced by fresh bulk fluid. After suitable dilution the samples were analyzed spectrophotometrically at a wavelength of 327 $\mathrm{nm}$. All experiments were carried out at $21 \pm 0.5^{\circ} \mathrm{C}$.

\section{Experiments with suppositories}

The percentage of zomepirac sodium dihydrate (10\%) released from suppositories was determined in a modified USP XX paddle apparatus. An open glass tube (diameter: $37.6 \mathrm{~mm}$ ) was mounted in such a way in this apparatus that the distance between the bottom of a suppository, fixed beneath the bulk surface inside the tube. and the bottom of the tube was at least $2 \mathrm{~mm}$. The suppositories were kept in position by a needle; the top of the glass tube was covered by a plastic cap. The temperatures of the phase inside the tube and of the bulk fluid were regisiered using small thermopiles (diameter $<1.5 \mathrm{~mm}$ ). The difference between these temperatures was always less than $0.1^{\circ} \mathrm{C}$. The temperature of the bulk fluid is given in the text. The rotational speed of the paddle was $30 \mathrm{rpm}$. Sampling procedure and analysis were analogous to those described for suspensions.

\section{Results and Discussion}

Suspensions of zomepirac and zomepirac sodium dihydrate in liquid paraffin were prepared and the release rates of these two compounds were measured in the apparatus described before (see Methods). The results obtained were used to predict the release from suppositories and in vitro experiments with suppositories were carried out in the modified USP-XX paddle apparatus (see Methods).

\section{(A) Experiments with liquid paraffin as the suspension vehicle}

Suspensions containing increasing concentrations of zomepirac or zomepirac sodium dihydrate were prepared and the release rates of the drugs from these suspensions were determined. These release rates were calculated from the steady state part of the curves, i.e. those parts of the concentration versus time curves where the release is not yet influenced by the exhaustion of the suspension (see Fokkens and De Blaey, 1982). An illustration of a typical concentration-time curve is given in Fig. 1.

As can be seen from this curve, the release of the drug is constant during a certain 


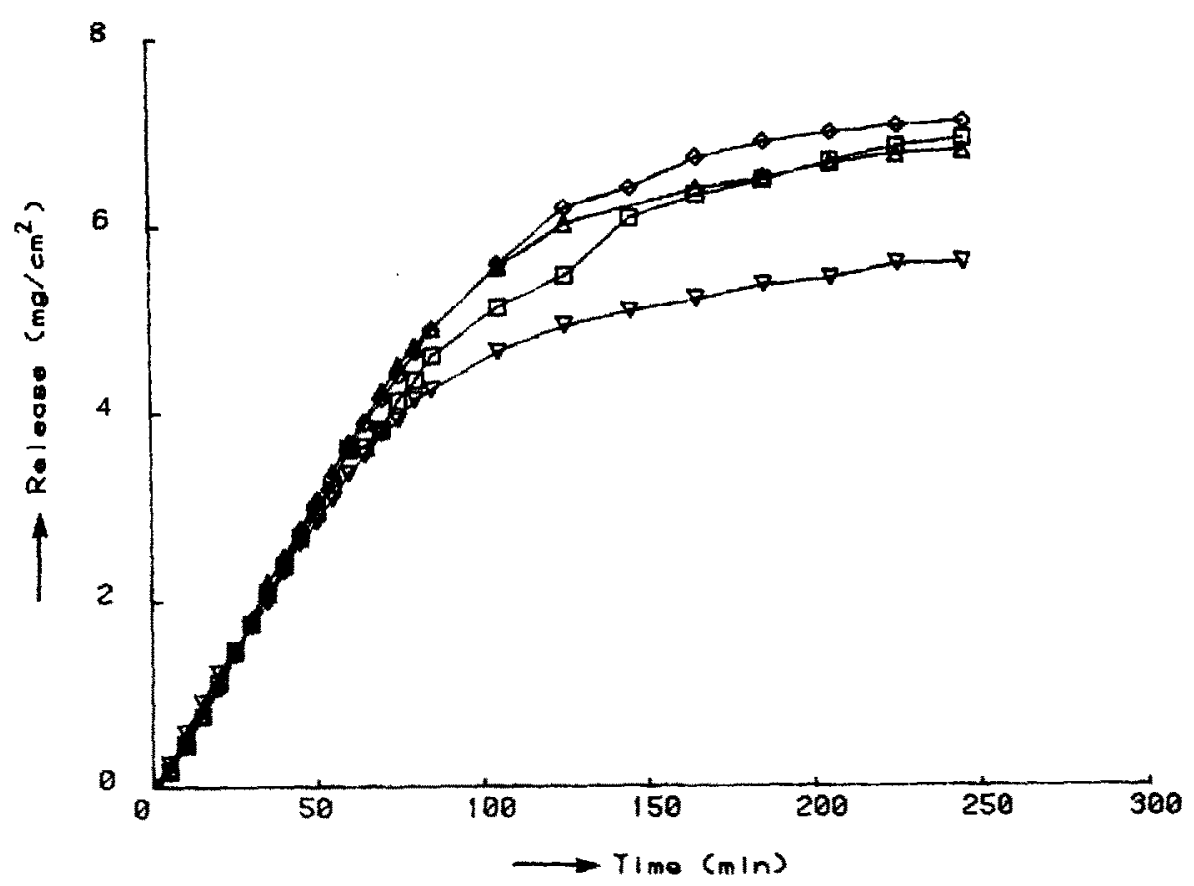

Fig. 1. Release of zomepirac sodium dihydrate from a 1 suspension in liquid parafrin to phosphate buffer with $\mathrm{pH}=7.4$. The curves represent a quadruple experiment.

time whereafter the curve flattens out due to exhaustion of the suspension. Finally a plateau concentration is reached (the suspension is 'empty'). In Fig. 2 the release of zomepirac and zomepirac sodium dihydrate from suspensions containing various concentrations of these compounds is shown; the data are presented in Table 2.

As can be seen from Fig. 2 the release process was dissolution rate-limited (see Fokkens and De Blaey, 1982) for all concentrations of zomepirac and zomepirac sodium dihydrate used. The release experiments were carried out with a $0.1 \mathrm{M}$ phosphate buffer as the aqueous phase. In order to find out whether the phosphate concentration had any influence on the release rate of zomepirac or zomepirac sodium dihydrate, this concentration was varied from 0.01 to $0.1 \mathrm{M}$ and the release of zomepirac and zomepirac sodium dihydrate was determined. The results obtained in this study are shown in Fig. 3 and the release rates are given in Table 3.

From the data given in Table 3 it is obvious that, in the case of the release of zomepirac, the release rate increases with increasing phosphate concentration. whereas in the case of zomepirac sodium dihydrate there is a decrease in the release rate. This phenomenon is probably related to the buffering effect of the phosphate ions on the 'surface' of the dissolving compounds. In the case of zomepirac, the pH normally 'created' at the dissolving surface will be approximately 4.2. By increasing the concentration of phosphate ions the buffer capacity will increase, resulting in a higher $\mathrm{pH}$ at the interface and thus an increased solubility of zomepirac. In the case of zomepirac sodium dihydrate, however, the $\mathrm{pH}$ at the surface of the dissolving 


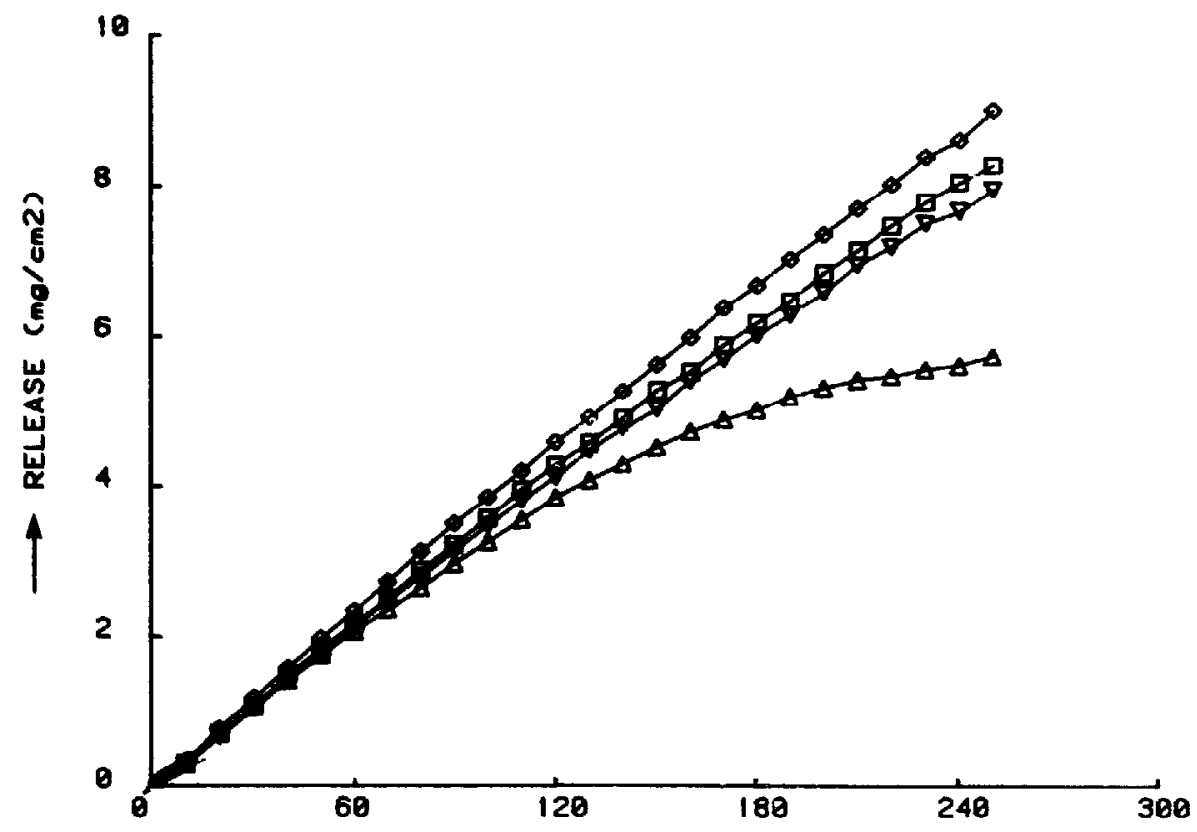

ZOMEPIRAC-Na.2Oa

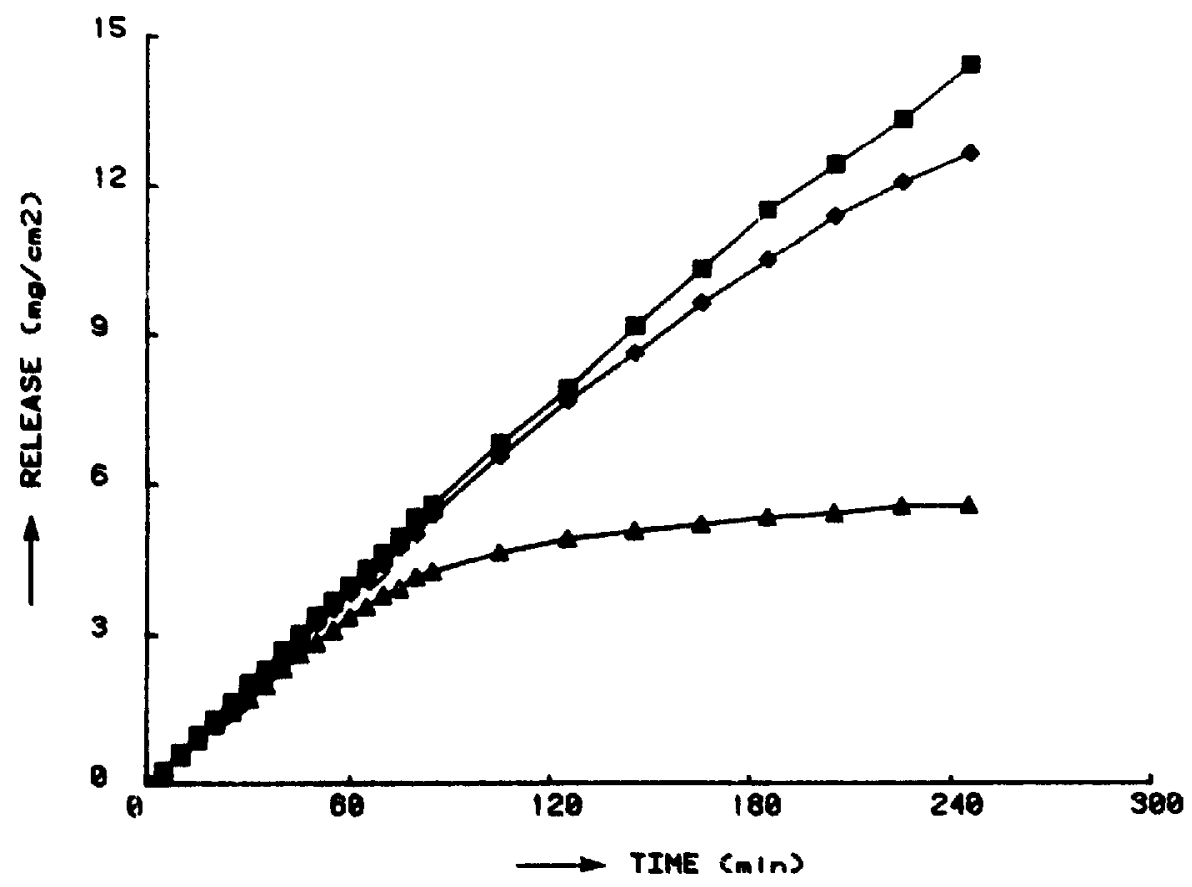

Fig. 2. The release of various concentrations of zomepirac and zomepirac-Na.2 aq from suspensions in liquid paraffin to a $0.1 \mathrm{M}$ phosphate buffer with $\mathrm{pH}=7.4 . \Delta, 1 \% ; \nabla, 3 \% ; \square, 5 \% ; 0,10 \%$. Open symbols zomepirac; closed symbols zomepirac-Na.2 aq. 


\section{ZOMEPIRAC}

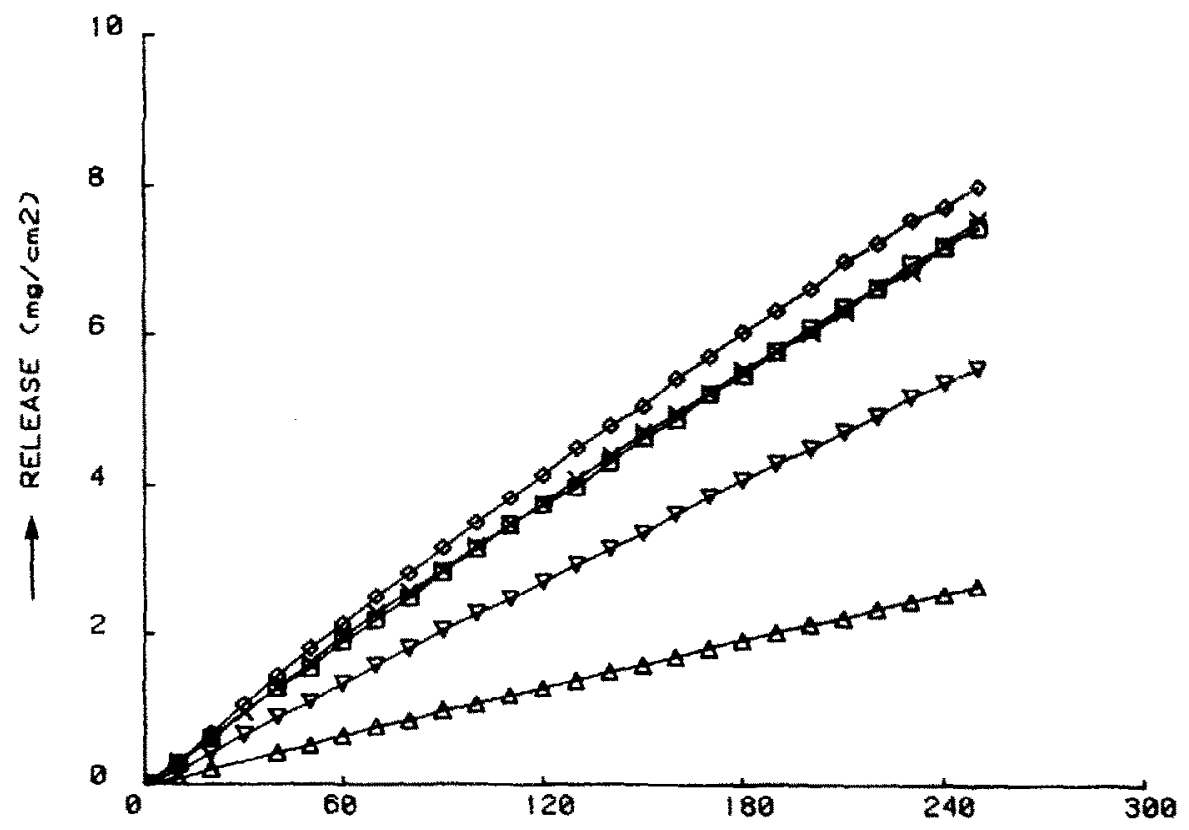

ZOMEPIRAC-Na. 209

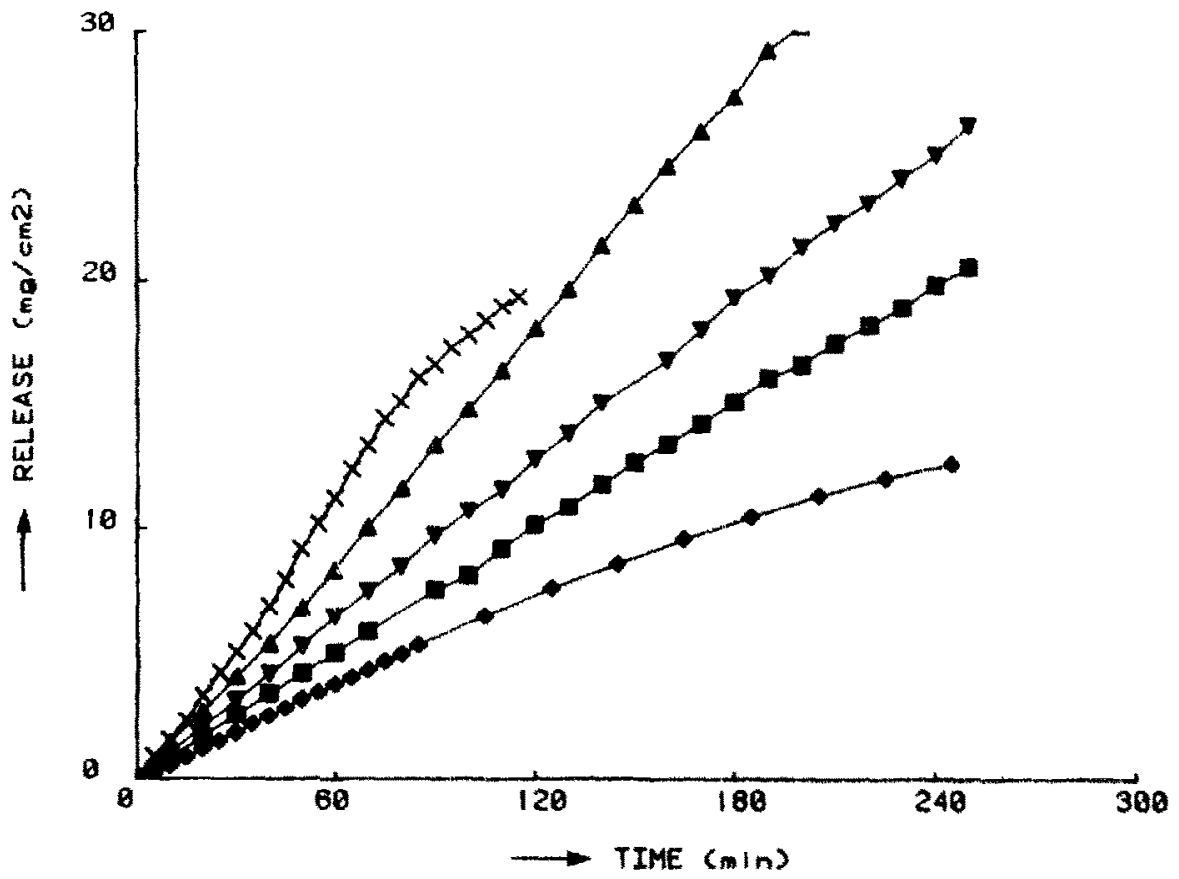

Fig. 3. The release of zomepirac ( $3 \%)$ and zomepirac-Na.2 ay (10\%) from suspensions in liquid paraffin to various aqueous phases (i.e. phosphate buffer $=p b$. or Tris-HCl buffer $=$ (b.) $4.0 .01 \mathrm{M}$ p.: $\nabla .0 .04 \mathrm{M}$ ph.: [1. 0.07 M pb.: 0. $0.10 \mathrm{M} \mathrm{pb.:} \times .0 .10 \mathrm{M} \mathrm{th}$. 
TABLE 2

RELEASE RATES $\left(\mathrm{mg} \cdot \mathrm{cm}^{-2} \cdot \mathrm{min}^{-1}\right)$ OF ZOMEPIRAC AND ZOMEPIRAC-NA DIHYDRATE FROM PARAFFIN SUSPENSIONS TO $0.1 \mathrm{M}$ PHOSPHATE BUFFER WITH $\mathrm{pH}=7.4(\mathrm{n}=4)$

\begin{tabular}{lllll}
\hline Compound & \multicolumn{4}{l}{ Concentration } \\
\cline { 2 - 5 } & $1 \%$ & $3 \%$ & $5 \%$ & $10 \%$ \\
\hline Zomepirac & $0.034 \pm 0.001$ & $0.034 \pm 0.002$ & $0.036 \pm 0.001$ & $0.039 \pm 0.002$ \\
Zomepirac-Na dihydrate & $0.061 \pm 0.003$ & - & $0.065 \pm 0.003$ & $0.063 \pm 0.005$ \\
\hline
\end{tabular}

The differences between the release rates were not significant, except for the $1 \%$ and $10 \%$ zomepirac concentration.

particles will be higher than 7.4 and an increase in the phosphate concentration and thus the buffer capacity will cause a decrease of the $\mathrm{pH}$ at the dissolving surface. This will result in a lower solubility. In order to circumvent this problem, studies were carried out with $0.1 \mathrm{M}$ Tris- $\mathrm{HCl}$ buffer $(\mathrm{pH}=7.4)$ as the aqueous phase. The release rates measured for zomepirac and zomepirac sodium dihydrate were now 0.031 and $0.171 \mathrm{mg} /\left(\mathrm{cm}^{2} \cdot \mathrm{min}\right)$, respectively. Since the buffer capacity of the $0.1 \mathrm{M}$ Tris buffer is higher than that of the $0.04 \mathrm{M}$ phosphate buffer but lower than the $0.07 \mathrm{M}$ buffer it was expected that the release rates measured for zomepirac and zomepirac sodium dihydrate would lie between the rates found with these buffers (see Table 3). For the acid this was the case. For zomepirac sodium dihydratc. however, there was no such correlation. So the phenomenon observed with the phosphate buffers cannot be explained on the basis of buffer capacity alone.

\section{The influence of calcium ions on the release rate}

Calcium ions react with zomepirac to form an almost insoluble salt. So when zomepirac or zomepirac sodium dihydrate is given rectally the physiologically present calcium will react with the drug the moment this is delivered from the dosage form. This may lead to the formation of a cake in the interfacial layer between vehicle and rectal fluid. Crystallization effects in an interfacial layer leading to the formation of a cake were observed in previous studies with phenobarbital and theophylline (Fokkens and De Blaey, 1982; Fokkens and De Blaey, 1984). The influence of calcium on the release rate of zomepirac and zomepirac sodium dihydrate was determined; the results are given in Table 4 . The experiments were carried out with Tris- $\mathrm{HCl}$ buffer or demineralized water as the aqueous phase.

As can be seen from the results presented in Table 4 the release process decreases considerably when calcium is added to the aqueous phase. The formation of a white cake in the interfacial layer was observed macroscopically. Sumetimes this cake broke loose from the interface, whereafter the release process immediately increased. When the Ca-concentration in the bulk was sufficiently high, however, a new cake formed within a few minutes. In order to improve the release of the drug, additives were added to the suspension. The 3 compounds chosen were lecithin, Tween 80 and polyvinylpyrrolidone (PVP). Lecithin was chosen because it is often used in commercially available suppository bases. Tween 80 can influence both the interfacial 
TABLE 3

RELEASE RATES $\left(\mathrm{mg} \cdot \mathrm{cm}^{-2} \cdot \mathrm{min}^{-1}\right)$ OF ZOMEPIRAC AND ZOMEPIRAC-Na DIHYDRATE FROM 3\% AND 10\% PARAFFIN SUSPENSIONS, RESPECTIVELY.

\begin{tabular}{llllll}
\hline Compound & \multicolumn{2}{l}{ Concentration of the phosphate buffer $(\mathrm{M})$} & Tris buffer \\
\cline { 2 - 6 } & 0.01 & 0.04 & 0.07 & 0.10 & $0.10 \mathrm{M}$ \\
\hline Zomepirac & $0.0108 \pm 0.0002$ & $0.0234 \pm 0.0013$ & $0.0316 \pm 0.0006$ & $0.034 \pm 0.002$ & $\mathbf{0 . 0 3 1}$ \\
Zomepirac-Na dihydrate & $0.144 \pm 0.008$ & $0.109 \pm 0.003$ & $0.083 \pm 0.003$ & $0.063 \pm 0.005$ & 0.171 \\
\hline
\end{tabular}

With the phosphate buffer $(n=4)$, the data measured with the Tris buffer is the mean of two experiments. The $\mathrm{pH}$ of the aqueous phase was 7.4.

tension and the wettability of the compounds used. This can lead to an increased release rate, but is likely to hinder the formation of the cake of zomepirac calcium. since an increase in the release rate will disturb the hydrodynamical situation in the interfacial layer (Fokkens, 1983). Polyvinylpyrrolidone was chosen for its crysiallization-inhibiting properties. The influence of these 3 compounds on the release rates of zomepirac and zomepirac sodium dihydrate under several circumstances was measured and the results are summarized in Table 5.

As can be seen from the results presented in Table 5, the addition of lecithin to a zomepirac suspension results in a decrease in the release of zomepirac. Addition of Tween 80 or PVP also resulted in a decreased release of zomepirac, but this cecrease was not as large as with lecithin. When $1 \mathrm{mmol}$ calcium was introduced into the aqueous phase the release of zomepirac decreased still further. This effect was relatively large for Tween 80 (compared with PVP as additive).

In the case of a zomepirac sodium dihydrate suspension all 3 additives caused an increase in the release of zomepirac sodium dihydrate. The effect of Tween 80 was greater than that of lecithin, which in its turn was larger than that of PVP. Addition of $1 \mathrm{mmol}$ calcium to the aqueous phase resulted in a decrease in the release of zomepirac sodium dihydrate when lecithin or Tween 80 were co-suspended. With PVP in the suspension no effect was observed on the release of zomepirac sodium dihydrate. When lecithin was used as additive the release of zomepirac sodium

TABLE 4

RELEASE OF ZOMEPIRAC 10\% AND ZOMEPIRAC-Na DIHYDRATE 10\% FROM PARAFFIN SUSPENSIONS TO AQUEOUS PHASES WITH AND WITHOUT CALCIUM

\begin{tabular}{llll}
\hline $\begin{array}{l}\text { Ca added to the } \\
\text { aqueous phase }\end{array}$ & \multicolumn{2}{l}{ Release rate observed of $\left(\mathrm{mg}^{\circ} \cdot \mathrm{m}^{2} \cdot \mathrm{min}^{\prime \prime}\right)$} & Aqueous phase \\
\cline { 2 - 4 } & Zomepirac & Zomepirac-Na dihydrate & \\
\hline & 0.031 & 0.171 & Tris \\
$1 \mathrm{mmol}$ & 0.007 & 0.024 & Tris \\
$1 \mathrm{mmol}$ & - & 0.017 & demineralized walter \\
& & 0.149 & demineralized water \\
\hline
\end{tabular}

The data represent the mean of two experinents. 
dihydrate was practically reduced to zero. When Tween 80 was used the release rate of zomepirac sodium oihydrate was reduced to approximately $70 \%$ of the initial value. From these results it was concluded that the effect of Tvieen 80 or PVP on the release rate of zomepirac sodium dihydrate was positive, even when there was calcium in the aqueous phase. The effect of lecithin, however, seemed to be rather questionable when calcium was involved.

In order to obtain an increased release rate of zomepirac sodium dihydrate from suppository bases, we studied the release from several of these bases.

\section{(B) Experiments with several suppository bases as the suspension vehicle}

The release of zomepirac sodium dihydrate from several suppository bases was measured in a modified USP XX paddle apparatus (see Methods). The suppositories were placed in an open glass tube in order to be sure that the hydrodynamical situation was reproducible (see Fokkens and De Blaey. 1984). The amounts of zomepirac sodium dihydrate released from the suppositories at certain time intervals are presented in Table 6. The release rate per unit area could not be given since the suppositories did not always spread over the entire surface of the glass tube.

From the results presented in Table 6, one can conclude that the release of zomepirac sodium dihydrate from the Witepsol-H15 base was far from complete after $90 \mathrm{~min}$. The release of zomepirac sodium dihydrate from the Novata and Suppocire bases was rather good. The release from the Suppocire AP bases was especially fast: however, it should be noted that the buffer phase became turbid. Probably this can be ascribed to the formation of an emuision, since this Suppocire bases has strong emulsifying properties. As can be seen also from the results presented in Table 6 the release of zomepirac sodium dihydrate was decreased to a large extent when $1 \mathrm{mmol}$ calcium was added to the aqueous phase. This phenomenon occurred when Novata 299 or Suppocire AlM were used as vehicle. When Suppocire AP was used, however, no influence at all on the release rate was measured. This was again explained by the emulsifying properties of the vehicle, resulting in a turbid emulsion as aqueous phase. So in this case the formation of a cake of zomepirac calcium was prevented. As shown in the experiments with zomepirac sodium dihydrate in liquid paraffin, the addition of calcium had a considerable influence on the release of zomepirac sodium dihydrate. In order to find out to what extent calcium and PVP, Tween 80 and lecithin influence the release of zomepirac sodium dihydrate from suppositories, experiments were carried out using Novata 299 as the suppository base. In this base the additives were co-suspended and the release of zomepirac sodium dihydrate to demineralized water with or without calcium was measured. The results of these experiments are presented in Table 7.

From the results presented in Table 7 it is obvious that the release of zomepirac sodium dihydrate is decreased when calcium is added to the aqueous phase. On the basis of the results obtained with zomepirac sodium dihydrate suspended in liquid paraffin (Table 5), it was expected that addition of $1 \%$ lecithin would have no influence on the release process. Addition of 1\% PVP or 1\% Tween 80 would 
TABLE 5

RELEASE RATES $\left(\mathrm{mg} \cdot \mathrm{cm}^{-2} \cdot \mathrm{min}^{-1}\right)$ OF ZOMEPIRAC $10 \%$ AND ZOMEPIRAC SODIUM DIHYDRATE 10\% FROM PARAFFIN SUSPENSIONS, CONTAINING LECITHIN, TWEEN 80 OR POLYVINYLPYRROLIDONE

\begin{tabular}{llll}
\hline Compound & $\begin{array}{l}\text { Calcium } \\
\text { added } \\
(\mathrm{mol})\end{array}$ & $\begin{array}{l}\text { Release rate } \\
\left(\mathrm{mg} \cdot \mathrm{cm}^{-2} \cdot \mathrm{min}^{-1}\right)\end{array}$ & Aqueous phase \\
\hline
\end{tabular}

(A) Additive: I\% lecithin

Zomepirac acid

Zomepirac-Na dihydrate

$\begin{array}{lc}\overline{1 \mathrm{mmol}} & <0.0004 \\ & <0.0004 \\ 1 \mathrm{mmol} & 0.688 \\ \overline{1 \mathrm{mmol}} & 0.020 \\ 1 \mathrm{~mm} & 0.552 \\ \overline{\mathrm{a}}^{\mathrm{m}} & 0.013 \\ 1 \mathrm{mmol} & 0.599 \\ & 0.014\end{array}$

Tris
Tris
Tris
Tris
demineralized water
demineralized water
demineralized water
demineralized water

(B) Additive: $1 \%$ Tween 80

Zomepirac acid

$\begin{array}{lll}- & 0.026 & \text { Tris } \\ 1 \mathrm{mmol} & 0.009 & \text { Tris } \\ - & 0.95-1.0 & \text { Tris } \\ 1 \mathrm{mmol} & 0.655 & \text { Tris } \\ - & 0.699 & \text { demineralized water } \\ 1 \mathrm{mmol} & 0.786 & \text { demineralized water } \\ 5 \mathrm{mmol} & 0.007 & \text { demineralized water } \\ 10 \mathrm{mmol} & <0.001 & \text { demineralized water }\end{array}$

(C) Additive: $1 \%$ polyuinylpyrrolidone

Zomepirac acid

\begin{tabular}{lll}
- & 0.017 & Tris \\
$1 \mathrm{mmol}$ & 0.012 & Tris \\
$\overrightarrow{1}$ & 0.192 & Tris \\
\hline $\mathrm{mmol}$ & 0.114 & Tris \\
$1 \mu \mathrm{mol}$ & 0.220 & demineralized water \\
$50 \mu \mathrm{mol}$ & 0.210 & demineralized water \\
$1 \mathrm{mmol}$ & 0.235 & demineralized water \\
$5 \mathrm{mmol}$ & 0.230 & demineralized water \\
& $<0.008$ & demineralized water
\end{tabular}

The aqueous phase was Tris-buffer or demineralized water; the calcium-concentration of the aqueous phase was varied.

${ }^{4} 0.5 \%$ lecithin.

influence the release process. In the case of lecithin and Tween 80 the results comply with the expectations. However, in the case of 1\% PVP as additive there was no increase in the release of zomepirac sodium dihydrate, although an increase with respect to the results obtained before was expected (see Tables 4 and 5). In conclusion it can be said that the release of zomepirac sodium dihydrate from suppositories to a calcium-containing aqueous phase is very low. This release can be improved by the addition of $1 \%$ Tween 80 to the suppository base. Co-suspended lecithin or PVP has no effect on the release of zomepirac sodium dihydrate towards a calcium containing aqueous phase. 
TABLE 6

PERCENTAGE OF ZOMEPIRAC SODIUM DIHYDRATE RELEASED FROM SEVERAL SUPPO. SITORY BASES AT CERTAIN TIME INTERVALS

\begin{tabular}{|c|c|c|c|c|c|}
\hline \multirow[t]{2}{*}{ Suppository bases } & \multirow[t]{2}{*}{$\begin{array}{l}\text { Calcium } \\
\text { added }\end{array}$} & \multicolumn{3}{|c|}{$\begin{array}{l}\text { Amount of zomepirac } \\
\text { sodium dihydrate released } \\
\text { at } t \text { (min) }\end{array}$} & \multirow[t]{2}{*}{$\begin{array}{l}\text { Temperature } \\
\left({ }^{\circ} \mathrm{C}\right)\end{array}$} \\
\hline & & 30 & 60 & 90 & \\
\hline I Witepsol H15 & - & 18 & 38 & 59 & 37.4 \\
\hline II Witepsol W32 & - & 8 & 10 & 12 & 37.0 \\
\hline III Novata 299 & - & 40 & 90 & 110 & 37.5 \\
\hline Novata 299 & + & 8 & 15 & 23 & 37.4 \\
\hline IV Novata $299+$ Novata AB (10\%) & - & 27 & 72 & 95 & 37.1 \\
\hline \multirow[t]{2}{*}{ V Suppocire AP } & - & 68 & 102 & 105 & 37.3 \\
\hline & + & 100 & 110 & 110 & 37.4 \\
\hline \multirow{2}{*}{$\begin{array}{l}\text { VI Suppocire AIM } \\
\text { (phosphate buffer) }\end{array}$} & - & 35 & 95 & 110 & 37.2 \\
\hline & + & 10 & 20 & 24 & 37.4 \\
\hline
\end{tabular}

The aqueous phase was Tris buffer, $\mathrm{pH}=7.4$

TABLE 7

PERCENTAGE OF ZOMEPIRAC-Na DIHYDRATE RELEASED FROM NOVATA 299 SUPPOSITORY BASE

\begin{tabular}{lllrr}
\hline Suppository base & I mmol calcium added & \multicolumn{3}{c}{ Percentage released at time $(\mathbf{m i n})$} \\
\cline { 3 - 5 } & & 30 & 60 & 90 \\
\hline Novata 299 & - & 60 & 100 & 100 \\
Novata 299 & + & 10 & 20 & 30 \\
$\quad+10$ lecithin & + & 18 & 26 & 32 \\
$\quad+1 \%$ PVP & + & 15 & 21 & 30 \\
$\quad+18$ Tween 80 & + & 35 & 70 & 90 \\
\hline
\end{tabular}

The aqueous phase was demineralized water.

\section{Acknowledgement}

The authors wish to thank Miss Irma Pielage for her careful execution of the experiments. They also thank Cilag $A G$ for financial support.

\section{References}

Fokkens, J.G., In Vitro Drug Release from Non-Aqueous Suspensions, Pn.D. Thesis. February 1983, Utrecht. The Netherlands

Fokkens, J.G. and De Blaey, C.J., Drug release from non-aqueous suspensions I. Release of phenobarbital and phenobarbital sodium from paraffin suspensions. Parm. Weekbl. Sci. Edn., 4 (1982) 117-121

Fokkens, J.G. and De Blaey, C.J., Drug release from non- cqueous suspensions II. The release of methylxanthines from paraffin suspensions. Int. J. Pharm., 8 (1984) 127-138. 